\title{
Effect of Guided Inquiry Teaching Method on Secondary School Students' Achievement in Light and Sound Waves in Abuja, Nigeria
}

\section{Ekomaye, Daniel Gideon}

Department of Science, Technology and Mathematics Education, Nasarawa State University, Keffi, Nigeria. Email: gideonehomave@gmail.com Tel:+23408076668474

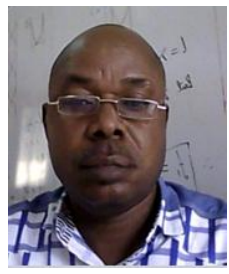

\section{Abstract}

This study was carried out to determine the effect of guided inquiry teaching method (GITM) on secondary school students' achievement in light and sound waves in Abuja, Nigeria. A sample of 95 students drawn from a population of 1,832 was used for the study. Two research questions were raised and answered in the study using mean and standard deviation while two hypotheses formulated were tested using ANCOVA at 0.05 level of significant. Quasi-experimental research design comprising experimental and control groups was used for the study. The instrument for data gathering was light and sound waves achievement test (LASWAT). A validity index of 0.86 and a reliability index of 0.87 were respectively obtained for LASWAT. Students in both groups were given pre-test before instruction. During the instruction, the same content was presented to the two groups for a period of six weeks and thereafter a post-test was administered. The findings of the study revealed that the experimental group significantly scored higher in post-test than the control group. This is evidenced in $\mathrm{Ho1}, \mathrm{F}(1,93)=85.476$ and $\mathrm{P}=0.000<\propto=0.05$. The results also showed that gender has no significant influence on mean achievement scores of students taught light and sound waves using GITM as revealed in $\mathrm{HO} 2, \mathrm{~F}(1,48)=0.656$ and $\mathrm{P}=0.413>\propto$ $=0.05$. The findings simply imply that GITM is superior to the conventional method in enhancing students' achievement in light and sound waves irrespective of gender in Abuja. Nigeria.

Keywords: Guided inquiry, Teaching method, Secondary, Students, Achievement, Light waves, Sound waves, Abuja, Nigeria

Citation | Ekomaye, Daniel Gideon (2019). Effect of Guided Inquiry Teaching Method on Secondary School Students Achievement in Light and Sound Waves in Abuja, Nigeria. Journal Education and e-Learning Research, 6(2): 82-87. History:

Received: 23 January 2019

Revised: 28 February 2019

Accepted: 30 April 2019

Published: 3 July 2019

Licensed: This work is licensed under a Creative Commons

Attribution 3.0 License (cc) J

Publisher: Asian Online Journal Publishing Group
Funding: This study received no specific financial support.

Competing Interests: The author declares that there are no conflicts of interests regarding the publication of this paper.

Transparency: The author confirms that the manuscript is an honest, Transparency: The author confirms that the manuscript is an honest,
accurate, and transparent account of the study was reported; that no vital accurate, and transparent account of the study was reported; that no vital
features of the study have been omitted; and that any discrepancies from the features of the study have been omitted;
study as planned have been explained.

Ethical: This study follows all ethical practices during writing.

\section{Contents}

1. Introduction

2. Result 85

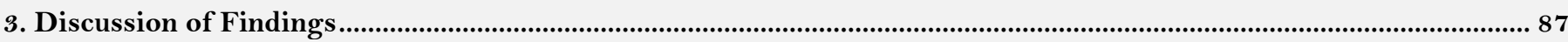

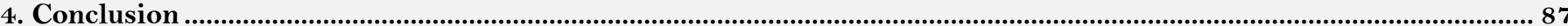

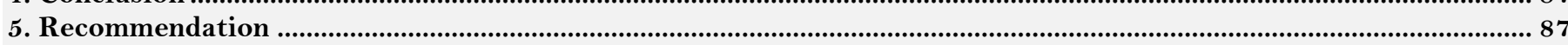

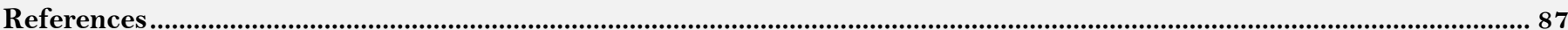




\section{Contribution of this paper to the literature}

This study contributes to existing literature by determining the effect of guided inquiry teaching method (GITM) on secondary school students' achievement in light and sound waves in Abuja, Nigeria.

\section{Introduction}

The technological development of any nation is based on science and technology. Without a solid foundation in the science, no nation can attain her developmental goals in this scientific world. One of the major science subjects in the secondary school system in Nigeria is physics. Physics is the part of science that deals with the behaviour of matter (Nelkon, 1997). Some of its branches are electricity, heat, sound, properties of matter, waves and wave optics and atomic physics. Many of the invention, appliances, tools, and buildings we live with today are made possible by the applications of physics principles. Above all, Physics is a prerequisite for admission into universities to read science related courses such as medicine, engineering, computer science, pharmacy, building and many others.

One major branch of secondary school physics in Nigeria is light and sound waves. Light is a wave in motion and it travels in a straight line at a very high speed. Sound wave is a disturbance generated by an object that is vibrating. Sound wave is generated as a result of the back and forth vibrations of the particles of a medium. The importance of light and sound waves in modern technology and in our everyday lives cannot be over emphasized. For example, light waves is applied in early detection of cancer, capturing flames, multifunction sensors for smartphones, exploring an asteroid. Effects of light travelling in straight lines are the formation of shadows, eclipses and images in mirrors. Plane mirrors are applied in devices such as sextant, kaleidoscope and periscope. Convex mirror is used as a security mirror in departmental stores and also as a driving mirror while concave mirror is used as a satellite dish, torch and vehicle head-lamp, shaving mirror. Sound waves help in communications, echo system, removal of gases from liquids, music, sterilization (killing of bacteria), determining the depth of ocean and many more.

Despite the importance of light and sound waves in modern technology, students' achievement in physics in Nigeria secondary schools have been at average level. For example, the West African Senior School Certificate Examination (WASSCE) results between 2013 and 2017 revealed that many candidates performed on average level in Abuja, Nigeria. Within this period, an average of 3,115 students in government owned secondary schools registered and sat for physics in WASSCE in Abuja. Out of this number, an average of 1,669 students (53.56\%) passed at credit level and above (A1-C6), 932 students (29.93\%) had ordinary pass (D7-E8) and 514 students (16.51\%) failed (F9). Details are shown in Table 1.

Table-1. Five -Years Entries/Results showing students' performance in physics in the May / June 2013/2017 WASSCE in Abuja -

\begin{tabular}{c|c|c|c|c}
\hline Year & Entries for physics & \% passes at credit Level (A1-C6) & \% of passes(D7-E8) & \% of failure(F9) \\
\hline 2013 & 2,842 & 41.66 & 37.44 & 20.9 \\
\hline 2014 & 2,479 & 50.4 & 31.59 & 18.01 \\
\hline 2015 & 3,114 & 41.49 & 36.1 & 22.41 \\
\hline 2016 & 3,382 & 65.47 & 23.83 & 10.7 \\
\hline 2017 & 3,762 & 68.78 & 20.67 & 10,55 \\
\hline
\end{tabular}

Despite the improvement recorded in 2016 and 2017, the average performance of students in physics within this period (2013-2017) is 53\% at credit level. This can be attributed to many factors such as learner related factors, content related factors, process related factors, teacher related factors and environment related factors. The concept of light and sound waves is one of the content related factors affecting students' achievement in physics. Light and sound waves are two major aspect of the secondary school physics curriculum in Nigeria that students find it difficult to comprehend and this might be one of the reasons they performed below average in the subject. West Africa Examination Council [WAEC] (2013) cited in Bello (2015) reported that candidates that offered physics performed poorly in the area of light waves, sound waves, electrolysis, writing of formulae as well as explanations of basic principles, concepts and their application.

Also, inappropriate teaching method (one of the process related factors) adopted by physics teachers in secondary schools in Nigeria is another factor contributing to poor achievement in physics (Eyenaka et al., 2013). Uwudia (2013); Mangal (2014) and Oluwasegun et al. (2015). Teaching method can be defined as an organized procedure in sharing knowledge. For any teaching method to be a success, it must relate the teacher and the learner to the subject matter. The common objective of every teaching method is to make lesson understandable and also interesting to the students. The often used method of teaching by many physics teachers in Nigeria Secondary Schools, including Abuja is the conventional method. The conventional method is very useful in teaching large classes, which is very common feature in most public schools in Nigeria (Neboh, 2009). Also, Okeke (2011) stated that most science teachers used the conventional method becomes it is about the easiest to deliver. The method allows the teacher to have full control of the lessons in the classroom and it allow for dissimilation of large information at given period.

The conventional method employed in the teaching of science, has some major flaws despite its advantages and this might be one of the causes of poor achievement in the sciences (Neboh, 2009). The conventional method, according to him has failed in the recognition of the uniqueness of the inquiring - based nature of science and the leaner individuality and it does not facilitate the development of reasoning skills and processes in the students leading to poor achievement 
The problem of inappropriate teaching methods and poor achievement in physics has led to the continuous search by researchers for an effective and result oriented teaching method for the teaching of physics. In view of this, and coupled with the perceived difficulty in understanding light and sound waves by physics students, this researcher investigated the effect of guided inquiry teaching method (GITM) on secondary school students' achievement in light and sound waves.

GITM is a teaching method that enables students to acquire knowledge on their own under the tutelage of a teacher. In GITM, the teacher chooses the concept to be learnt and goes further to guide the students to learn or investigate the concept. The teacher may start the lesson by posing a question or a problem to the students and thereafter guide them to arrive at the solution. By so doing, the students are actively involved in the lesson thereby reducing the tendency of presenting established facts to them. The goal of GITM is to establish science process skills in the students and also enhance learning through students' active participation and investigation.

Many related studies have been carried out in some subjects, including physics on the effect of GITM on students' achievement.

For example, Ukamaka (2013) revealed that GITM is superior to conventional method in facilitating students' achievement in basic science. Also, his result revealed that there is no significant difference in the mean scores of male and female students taught basic science using guided inquiry. Similarly, Anayo (2014) and Musa (2015) in their separate investigations revealed that students taught light waves using GITM achieved higher than those taught using the conventional method. Also, Adejo (2015) showed that chemistry students taught using inquiry method performed significantly higher than their counterparts exposed to traditional method.

Uzezi and Zainab (2017) revealed in their findings that gender has no significant effect on academic achievement of students exposed to chemistry through guided inquiry laboratory experiment. However, the results of Adebayo (2016) showed that students taught physics using the conventional method achieved higher than those exposed to GITM. He revealed further that there is no significant difference in the mean scores of male and female students exposed to GITM.

\subsection{Statement of the Problem}

The consistent below average performance of students in physics in secondary schools in Abuja, Nigeria is the major problem that prompted this investigation. Physics is one of the key subjects in the study of science and technology courses. Therefore, if Nigeria is to attain her science and technological development, the problem of below average performance of students in physics must be addressed. Available research findings indicated that inappropriate teaching method used by physics teachers in Nigeria secondary schools and the difficulty encountered by students in comprehending the concepts of light and sound waves are some of the major factors responsible for the poor performance of students in the subject. Also available research findings showed that most physics teachers in secondary schools in Nigeria used the conventional methods in delivering their lessons. The conventional method is teacher-centred and this might be one of the reasons for the below average performance of students in physics. From the foregoing, this study was carried out to establish the effect of GITM on secondary school students' achievement in light and sound waves.

\subsection{Objective of the Study}

The study is aimed at finding the effect of GITM on secondary school students' achievement in light and sound waves. Specifically, the study determined the:

i. $\quad$ effect of GITM and conventional method on secondary school students' achievement in light and sound waves;

ii. $\quad$ effect of gender on students' achievement in light and sound waves when they are exposed to GITM.

\subsection{Research Question}

The study was guided by the following research questions.

i. What are the mean achievement scores of students taught light and sound waves using GITM and those taught using conventional methods?

ii. Which sex has higher means achievement scores when they are taught light and sound waves using GITM?

\subsection{Research Hypotheses}

The following null hypotheses were tested at 0.05 level of significant.

$\mathrm{H}_{01}$ : There is no significant difference in the mean achievement scores of students taught light and sound waves using GITM and those exposed to conventional method.

$\mathrm{H}_{02}$ : There is no significant difference in the mean achievement scores of male and female students taught light and sound waves using GITM.

\subsection{Research Design}

Quasi-experimental research design was used for the study. The design comprises experimental and control groups with pre-test and post-test. In both groups, students in their intact classes were used for the study. The design is illustrated in Figure 1.

EG

CG
$\mathrm{O}_{1}$

$\mathrm{O}_{1}$

$\mathrm{X}_{2}$

Figure-1. Research design for the study
$\mathrm{O}_{2}$

$\mathrm{O}_{2}$ 
Where

$\mathrm{EG}=$ experimental group

$\mathrm{CG}=$ control group

$\mathrm{O}_{1}=$ Pre-test

$\mathrm{O}_{2}=$ post-test

$\mathrm{X}_{1}=$ treatment for experimental group

$\mathrm{X}_{2}=$ treatment for control group

The experimental group was taught using GITM while the control group was exposed to the conventional method.

\subsection{Population}

All ss2 physics students in all public co-educational secondary schools in Abuja Municipal Area Council (AMAC), Abuja made up the population for the study. As in third term, 2017/2018 academic session the population was 1,832 students,

\subsection{Sample and Sampling Technique}

The sample used for the study was 95 students ( 48 male and 47 female). The sample was obtained through hat and draw sampling method. Firstly all the public secondary schools in AMAC were identified and stratified into mixed and single sex schools. Secondly, from the mixed schools, schools with not more than one arm of SS2 physics class were listed out. The names of these schools listed were each written on a paper, folded and placed in a small empty bucket. Thirdly, a young girl was asked to randomly pick two folded papers (schools) from the bucket using hat and draw method

\subsection{Instrumentation}

The instrumentation used for data gathering was Light and Sound Waves Achievement Test (LASWAT). It was developed by the researcher and it was made up of 50 multiple choice test items. LASWAT was used for the collection of pre-test and post-test scores. All the questions and options in the LASWAT were reshuffled and the colour of the question paper was changed from white to yellow after the pre-test had been administered. LASWAT was subjected to face and logical velocity. Three experts, two in science education and one in measurement and evaluation validated the instrument. A validity index of 0.86 was obtained after the mean of the validators' rating was translated into logical validity index. To ensure content validity, a table of specification was constructed for LASWAT. To assess the essential qualities of the items that make up the instrument, item analysis was also carried out. The three aspects of item analysis done were item difficulty index, item discriminating index and distractors' analysis. To establish the degree of internal consistency of LASWAT, the test-retest method was used. KudarRichardson formula 20 (K-R 20) was used to established a reliability coefficient of 0.87 for LASWAT

\subsection{Administration of Data Gathering Instrument}

LASWAT was administered to the experimental and control groups in two stages. In the first stage (pre-test), LASWAT was administered to the two groups before the commencement of the treatment. This was done to find out students' initial knowledge of the concepts taught during the treatment. It was also done in order to ascertain the comparability of the two groups with respect to their achievement in the pre-test. The second stage of administration of LASWAT was done after a five weeks treatment period for the two groups. The major purpose of the post-test was to determine the achievement gain of the students in the two groups after the treatment

\subsection{Techniques for Data Analysis}

The two researched questions raised for the study were answered using descriptive statistics of mean and standard deviation while the two hypotheses formulated were tested using analysis of covariance (ANCOVA) at 0.05 level of significant.

\section{Results}

The results are presented in tables in line with the research questions raised and the corresponding hypothesis formulated for the study

Research Question 1: What are the mean achievement scores of students taught light and sound wave using GITM and those exposed conventional method?

Table-2. Mean achievement scores and standard deviation of experimental and control groups in LASWAT.

\begin{tabular}{c|c|c|c|c}
\multicolumn{2}{c}{ Table-2. Mean achievement scores and standard deviation of experimental and control groups in LASWAT. } & Post-test & Mean gain \\
\hline Group & Mean & Pre-test & 74.88 & 54.41 \\
\hline Experiment & Mean & 20.47 & 48 & \\
\hline & $\mathrm{N}$ & 48 & 10.465 & \\
\hline & Std. Deviation & 8.520 & 61.92 & 40.76 \\
\hline Control & Mea & 21.16 & 47 & \\
\hline & $\mathrm{N}$ & 47 & 12.392 & \\
\hline
\end{tabular}

The result in Table 2 shows that the experimental group had a mean achievement score of 20.47 at pre-test with a standard deviation of 8.520. The control group had a mean achievement score of 21.16 at pre-test with a standard deviation of 8.493. However at post-test, the experimental group had a mean score of 74.88 with a mean gain of 54.41 while the control group had a mean score of 61.92 with a mean gain of 40.76 . The difference in the mean scores of the two groups at post test is 12.96 in favour of the experimental groups. Also, there was a mean 
gain difference of 13.67 between the two groups in favour of the experimental group. These results show that the experimental group achieved higher than the control group.

To determine whether the observed difference in the post-test was significant or not, null hypothesis 1 was tested

\section{Null Hypothesis 1}

There is no significant difference in the mean achievement scores of students taught light and sound waves using GITM and those exposed to conventional method.

\begin{tabular}{c|c|c|c|c|c|c}
\multicolumn{7}{c}{ Table-3. ANCOVA analysis of mean achievement scores of students in experimental and control groups in LASWAT. } \\
\hline Source & Type 3 sum of square & DF & Mean Square & F & Sig. & Deci. \\
\hline Corrected model & 9984.010 & 2 & 4976.034 & 77.612 & .000 & $\mathrm{~S}$ \\
\hline Interest & 27149.110 & 1 & 29724.101 & 512.714 & .000 & $\mathrm{~S}$ \\
\hline Pre-test & 5647.831 & 1 & 5665.741 & 88.044 & .000 & $\mathrm{~S}$ \\
\hline Groups & 4974.172 & 1 & 4971.142 & 85.476 & .000 & $\mathrm{~S}$ \\
\hline Error & 5647.549 & 93 & 52.176 & & & \\
\hline Total & 482417.000 & 95 & & & & \\
\hline Corrected Total & 16457.648 & 94 & & & & \\
\hline
\end{tabular}

Table 3 indicates that there is a significant difference in the mean achievement scores of students in the experimental and control groups. This is based on the fact that the calculated F-value of 85.476 and with probability value of 0.000 which is less than the alpha value of 0.05 set for the study. That is $\mathrm{F}_{(1,93)}=85.476$ and $\mathrm{P}=$ $0.00<\propto=0.05$. To this effect, the null hypothesis $1\left(\mathrm{H}_{01}\right)$ is rejected. This implies that there is a significant difference in the mean achievement scores of students taught light and sound waves using GITM and those exposed to conventional method.

\section{Research Question 2}

Which sex has higher mean achievement scores when they are taught light and sound waves using GITM?

Table-4. Mean achievement scores and standard deviation of male and female students in experiental group.

\begin{tabular}{c|c|c|c|c}
\hline Gender Expt & Mean & Pre-test & Post-test & \\
\hline & Mean & 20.42 & 75.19 & 54.77 \\
\hline Male & $\mathrm{N}$ & 25 & 25 & \\
\hline & Std. Deviation & 7.329 & 10.200 & \\
\hline Female & Mean & 19.78 & 74.52 & 54.77 \\
\hline & $\mathrm{N}$ & 23 & 23 & \\
\hline
\end{tabular}

The result in Table 4 shows that male students in the experimental group had a mean achievement score of 20.42 at pre-test with a standard deviation of 7.329. Female students in the same experimental group had a mean achievement score of 19.78 at pre-test with a standard deviation of 9.702 . However at post-test, male students in the experimental group had a mean score of 75.19 with a mean gain of 54.77 while female students in the same experimental group had a mean score of 74.52 with a mean gain of 55.74 . The difference in the post-test mean scores of the two sexes is 0.67 . Also, there was a mean gain difference of 0.03 between the two sexes. These differences in the post-test mean scores and in the mean gain of the gender indicate that both male and female students performed almost equal at post-test when exposed to GITM.

To make a decision whether the observed difference in mean achievement by gender in experimental group is significant or not, null hypothesis 2 was tested.

\section{Null Hypothesis 2}

There is no significant difference in the mean achievement scores of male and female students taught light and sound waves using GITM.

\begin{tabular}{c|c|c|c|c|c|c} 
Table-5. ANCOVA analysis of mean achievement scores of male and female students taught light and sound waves. using GITM. \\
\hline Source & Type 3 sum of square & df & Mean square & F & Sig. & Dec. \\
\hline Corrected model & 2764.319 & 2 & 1328.178 & 33.642 & .000 & S \\
\hline Intercept & 19645.042 & 1 & 19704.021 & 512.242 & .000 & S \\
\hline Pre-test & 2742.374 & 1 & 2587.372 & 68.178 & .000 & S \\
\hline Gend Expt. & 27.062 & 1 & 25.081 & .656 & 0.413 & NS \\
\hline Error & 1964.534 & 48 & 37.471 & & & \\
\hline Total & 289412.000 & 51 & & & & \\
\hline Corrected Total & 4546.076 & 52 & & & & \\
\hline
\end{tabular}

Table 5 shows that there is no significant difference in the mean achievement scores of male and female students taught light and sound waves using GITM. This is evidenced in the calculated F-value of 0.656 and with probability value of 0.413 which is greater than the alpha value of 0.05 set for the study. That is, $\mathrm{F}_{(1,48)}=0.656$ and $\mathrm{P}=0.413>\propto=0.05$. Based on this, the null hypothesis $2\left(\mathrm{H}_{02}\right)$ is not rejected. This implies that there is no significant difference in the mean achievement scores of male and female students taught light and sound waves using GITM. 


\section{Discussion of Findings}

As revealed in Table 2, students taught using guided inquiry had higher mean achievement score at post-test than those exposed to conventional method and therefore they performed better. Also, Table 3 revealed that there is a significant difference in the mean achievement scores of students exposed to GITM and those taught using conventional method, in favour of those taught using GITM. This result supports the findings of Anayo (2014) and Musa (2015) who in their separate studies reported that students taught light waves using GITM achieved higher than those taught using the conventional method. Furthermore, the result of the study agrees with Ukamaka (2013) and Adejo (2015) who revealed in their separate findings that student taught basic science and chemistry using GITM achieved higher than those exposed to conventional method. However, the findings of this study is at variance with Adebayo (2016) who reported that students taught physics concepts using conventional method achieved higher than those exposed to guided inquiry.

As revealed in Table 4, there was no much difference in the post-test mean scores of male and female students taught using GITM. Furthermore Table 5 revealed that there is no significant difference in the mean achievement scores of male and female students taught light and sound waves using GITM. This result indicates that gender has no significant influence on students' achievement when exposed to GITM. This finding is in line with Ukamaka (2013); Adebayo (2016) and Uzezi and Zainab (2017) who in their separate findings revealed that gender has no significant effect on students' achievement when they are taught physics concepts using GITM.

\section{Conclusion}

Findings from this study revealed that students taught light and sound waves using GITM had higher mean scores than those exposed to conventional method. The method significantly enhanced students' achievement in light and sound waves than the conventional method. Also, findings from the study revealed that gender has no significant influence on students' achievement in light and sound waves when exposed to guided inquiry.

\section{Recommendation}

Based on the findings from the study, the following recommendations are made: Physics teachers in Abuja should adopt GITM in the teaching of light and sound waves in Abuja secondary schools and they should be given adequate training on how to use the method. Policy makers, school administrators and curriculum planners should consider GITM in the planning, designing and reviewing of Abuja secondary school physics curriculum, especially in the sub-topics of light and sound waves. Finally, more studies could be carried out on the effect of GITM on students' attitude and interest in light waves, effect of GITM on students' achievement and retention in other concepts in physics and in other science subjects.

\section{References}

Adebayo, K.O., 2016. Effect of guided inquiry on secondary school students' achievement and retention in physics. Unpublished PhD Thesis, University Calabar, Nigeria.

Adejo, L.O., 2015. Effect of inquiry method on academic performance of chemistry students in senior secondary schools in Kaduna State. Unpublished Master Degree Thesis, ABU, Zaria.

Anayo, E.G., 2014. Effect of guided inquiry teaching method on academic achievement of students in physics in Nasarawa State, Nigeria. Unpublished M.Ed Dissertation, Nasarawa State University, Keffi.

Bello, M., 2015. Impact of computer-aided instruction and enriched lecture method on interest and performance in physics among secondary school students in Zaria. Unpublished M.Ed Dissertation, ABU, Zaria, Nigeria.

Eyenaka, F., C. Ekanem and S. Uwak, 2013. Context-based teaching strategy (CBTS) for effective learning of simple alternating current (AC) circuits in senior secondary school Physics. Journal of Educational and Social Research, 3(8): 55-57.

Mangal, S.K., 2014. Essentials of educational psychology. Delhi: PHI Learning Private LTD.

Musa, M.A., 2015. Effect of guided inquiry and scaffolding teaching method on students' achievement and relation in physics in secondary schools in Kaduna State. Unpublished PhD Thesis, ABU Zaria, Nigeria.

Neboh, O.I., 2009. Effect of learning activity package (lap) on students' achievement and relation in senior secondary biology. Unpublished PhD Thesis, University of Nigeria, Nsukka, Nigeria.

Nelkon, M., 1997. Principles of physics for senior secondary schools. London: Longman Group Ltd.

Okeke, O.J., 2011. Effect of mind mapping teaching strategy on students' achievement, interest and relation in senior secondary school chemistry. Unpublished PhD Thesis, University of Nigeria, Nsukka, Nigeria.

Oluwasegun, G., O. Adrian and E. Johnbull, 2015. The impact of physics laboratory on students offering physics in Ethiope West Local Government Area of Delta State. Educational Research and Reviews, 10(7): 951-956.Available at: https://doi.org/10.5897/err2014.1943.

Ukamaka, U.T., 2013. Effect of guided inquiry method on students' achievement and interest in basic science. Unpublished M.Ed Desertation, University of Nigeria, Nsukka, Nigeria.

Uwudia, A., 2013. Teaching methods and learning outcomes in science. Paper Presented at a two-day Workshop for Science Teachers in IkaSouth Local Government Area, Delta State. Sept. pp: 6-7.

Uzezi, J.G. and S. Zainab, 2017. Effectiveness of guided inquiry laboratory experiment on senior secondary schools students' academic achievement in volumetric analysis. American Journal of Education Research, 5(7): 717-724. 